\title{
Little value in providing professional mechanical plaque removal without oral hygiene instruction
}

\author{
What is the effect of professional mechanical plaque removal (PMPR) on \\ clinical and patient centred outcomes related to the prevention of periodon- \\ tal diseases in adults?
}

\section{Needleman I, Suvan J, Moles DR, Pimlott J. \\ A systematic review of professional mechanical plaque removal for prevention of periodontal diseases. J Clin Periodontol 2005; 32 (Suppl. 6): 229-282.}

Data Sources Cochrane Central Register of Controlled Trials (CENTRAL), Medline, Old Medline, Embase and bibliographies of previously published review articles. Searching was limited to English language

Study Selection Randomized controlled trials (RCTs), controlled clinical trials (CCTs) and cohort studies with comparison groups were considered. Both parallel arm and split mouth treatment studies were eligible for inclusion and all durations of follow-up were included

Data Extraction and Synthesis Screening and data abstraction were conducted independently and in duplicate. Critical appraisal of studies was based on objective criteria and evidence tables were constructed and data stratified according to study type

Results From 2179 titles and abstracts, 132 full-text articles were screened and 32 studies were relevant. Evidence exists that PMPR in adults, particularly in combination with oral hygiene instruction $(\mathrm{OHI})$, may be more effective than no treatment judged by surrogate measures. The evidence for a benefit of PMPR + OHI over $\mathrm{OHI}$ alone is less clear. The optimum frequency of PMPR has not been investigated although more frequent PMPR is associated with improved markers of health. The strength of evidence for these results ranges from weak to moderate due to risk of bias, inconsistent results, lack of appropriate statistics and small sample size.

Conclusions There appears to be little value in providing PMPR without $\mathrm{OHI}$. In fact, repeated $\mathrm{OHI}$ might have a similar effect as PMPR. Some forms of PMPR might achieve greater patient satisfaction. There is little difference in beneficial or adverse effects of different methods of PMPR.

Address for Correspondence; Ian Needleman, International Centre for EvidenceBased Oral Health (ICEBOH), Department of Periodontology, Eastman Dental Institute, University College London (UCL),University of London, 256 Gray's Inn Road, London WC1X 8LD,UK.

\section{Commentary}

For more than 50 years the oral health anthem, sung by dentists to patients, was "brush and floss twice per day, and see your dentist twice a year". Now, this review on professional mechanical plaque removal (along with another review on flossing by Hujoel et al ${ }^{1}$ ), questions whether these interventions provide patients with an oral health benefit. Or more accurately, this review questions the data upon which this anthem is based.

The implications are profound. In the USA expenditures for preventive periodontal care are more than $\$ 14$ billion per year ${ }^{2}$. In an era when U.S. health care costs are expected to double over the next 7 years, curtailing this benefit would significantly impinge on a patient's expectations of care and a dentist's income. At the same time, with limited resources, from a governmental or insurers perspective, providing value for money is a paramount concern.

The study is based on review of more than 2000 randomized controlled trials, controlled trials, and cohort trials, reported between 1950 and 2004. The results indicate for plaque and gingivitis, but not pocket depth or attachment level, professional mechanical plaque removal + oral hygiene instruction is as effective as oral hygiene instruction alone, and both are better than no treatment. There is little evidence on the optimum frequency and little or conflicting evidence on the effects on pocket depth or attachment level. Table 1 summarizes the findings.

Table 1. Summary of the effects of the various interventions

\begin{tabular}{|c|c|c|c|}
\hline Intervention* & Comparison & $\begin{array}{l}\text { Plaque / } \\
\text { Gingivitis** }^{*}\end{array}$ & $\begin{array}{c}\text { Pocket } \\
\text { Depth / } \\
\text { Attachmen } \\
\text { Level }\end{array}$ \\
\hline Rubber cup & Air polish & $=$ & \\
\hline PMPR & No treatment & + & \\
\hline PMPR & $\mathrm{OHI}$ & $=$ & $=$ \\
\hline $\mathrm{PMPR}+\mathrm{OHI}$ & No treatment & + & \pm \\
\hline $\mathrm{PMPR}+\mathrm{OHI}$ & $\mathrm{OHI}$ & + & $=$ \\
\hline $\mathrm{PMPR}+\mathrm{OHI}$ & $\mathrm{SRP}+\mathrm{OHI}$ & - & $=$ \\
\hline PMPR + US & $\begin{array}{l}\text { PMPR + US + } \\
\text { Floss }\end{array}$ & $=$ & \\
\hline PMPR + US & PMPR + Curettes & + & \\
\hline PMPR + SRP & SRP & $=$ & \pm \\
\hline PMPR + SRP & $\mathrm{SRP}+\mathrm{OHI}$ & + & \pm \\
\hline $\begin{array}{l}\mathrm{PMPR}+\mathrm{SRP}+ \\
\mathrm{OHI}\end{array}$ & SRP & + & \\
\hline $\begin{array}{l}\mathrm{PMPR}+\mathrm{SRP}+ \\
\mathrm{OHI}\end{array}$ & $\mathrm{SRP}+\mathrm{OHI}$ & $=$ & $=$ \\
\hline
\end{tabular}

* $\mathrm{PMPR}=$ professional mechanical plaque removal; $\mathrm{OHI}=$ oral hygiene instruction; SRP = scale and root plane; US = ultrasonic.

${ }^{* *}=$ indicates intervention and comparison have equivalent effects; + indicates intervention has greater effect than comparison; - indicates intervention is less effective than comparison; \pm indicates that results among studies are variable. 
There are also some interesting and noteworthy contradictions, extrapolations, and limitations that this review raises. For example:

- Increased frequency of PMPR was not associated with increased health. In fact, the contrary was found. Increased frequency of PMPR could lead to increased attachment loss.

- The common practice in U.S. dental hygiene programs is to teach rubber cup prophylaxis. The data suggests that rubber cup and air polishing have equivalent efficacies.

- While PMPR + OHI appeared to be more effective than PMPR alone, recent reviews suggest that the efficacy of self performed plaque control is not optimal. 1,3

- The recent reviews ${ }^{4,5}$ comparing scaling and root planing + systemic antibiotics indicate that the combination is more effective than scaling and root planing alone. Given the current results, one wonders whether $\mathrm{OHI}+$ systemic antibiotics would be as effective as SRP + antibiotics.

- Other data associates periodontal disease with increased risk of systemic medical conditions ${ }^{6}$ (eg: pre-term low birth, cardiac disease, diabetic control, or stroke). One might have previously suspected that the periodontal intervention of choice would be scaling and root planing \pm surgery. The results of the current review, however, suggest that PMPR + OHI may be an effective preventive intervention. Preliminary data supporting this hypothesis was identified by Adachi ${ }^{7}$.

Finally, the identified studies were largely carried out in academic settings, were often underpowered, did not analyze smoking as a covariate, and did not include children. Thus, while the review presents the best available evidence, it also highlights the need for appropriately sized trials, carried out in clinical practice settings, of a duration long enough to demonstrate or refute effectiveness. From a patient's or clinician's perspective, this may be a mute point, the default perspective being, more prevention can't hurt. From a public health perspective, however, at an estimated U.S. cost for PMPR of $>\$ 28$ billion by 2014 , there will be significant pressure to demonstrate clinical effectiveness and significance.

\section{Richard Niederman, DMD}

The Forsyth Institute, 140 The Fenway, Boston, MA, USA, and

Boston University Goldman School of Dental Medicine, Boston, MA USA
1. Hujoel PP, Cunha-Cruz J, Banting DW, Loesche WJ. Dental flossing and interproximal caries: a systematic review. J Dent Res 2006; 85:298-305.

2. Brown LJ, Johns BA, Wall TP. The economics of periodontal diseases. Periodontol 2000. 2002; 29:223-34.

3. Hujoel PP, Cunha-Cruz J, Loesche WJ, Robertson PB. Personal oral hygiene and chronic periodontitis: a systematic review. Periodontology 2000. 2005; 37:29-34.

4. Haffajee AD, Socransky SS, Gunsolley JC. Systemic anti-infective periodontal therapy. A systematic review. Ann Periodontol. 2003 Dec;8(1):115-81.

5. Herrera D, Sanz M, Jepsen S, Needleman I, Roldan S. A systematic review on the effect of systemic antimicrobials as an adjunct to scaling and root planing in periodontitis patients. J Clin Periodontol. 2002;29 Suppl 3:136-59; discussion 160-2.

6. Dietrich T, Garcia RI. Associations between periodontal disease and systemic disease: evaluating the strength of the evidence.J Periodontol. 2005 Nov; 76(11 Suppl):2175-84.

7. Adachi M, Ishihara K, Abe S, Okuda K, and Ishikawa T. The effect of professional oral health care on the elderly living in nursing homes. Oral Surg, Oral Med, Oral Path, Oral Radiol. 2002; 94:191-195.

Evidence-Based Dentistry (2006) 7, 69-70.

doi:10.1038/sj.ebd.6400426 